\title{
Mapping peatland disturbance in Ireland: an object oriented approach
}

\author{
Connolly, J. ${ }^{1}$ and Holden, N. M.
}

\author{
UCD Bioresources Research Centre / Biosystems Engineering, Agriculture and Food Science \\ Centre, UCD School of Agriculture Food Science and Veterinary Medicine, University College \\ Dublin, Belfield, Dublin 4, Ireland
}

\begin{abstract}
Peatlands contain large amounts of soil organic carbon. In a pristine state they sequester atmospheric carbon dioxide $\left(\mathrm{CO}_{2}\right)$, however, when they are disturbed they emit it. In Ireland peatlands are extensive and cover $20 \%$ of the national land area. They contain between $53 \%$ and $62 \%$ of the total national soil organic carbon. However, large areas of Irish peatlands have been disturbed by anthropogenic activity. This activity includes drainage, mechanical extraction and burning. These activities lead to the reduction of the resilience of the peatland to climate and environmental change and can lead to the increased vulnerability of the peatland carbon stock. In this research an object oriented approach is used to examine high resolution imagery of a raised bog in Ireland and to extract a map of disturbed peatlands. The object oriented approach is implemented in ArcGIS with high resolution Geoeye-1 satellite imagery. The main disturbance classes identified were rough grazing, pasture, molinia, coniferous forest, high bog, drained bog and scrub. The users accuracy for each individual class ranged from $66 \%$ to $92 \%$ and the overall accuracy assessment for the disturbance map $85 \%$.
\end{abstract}

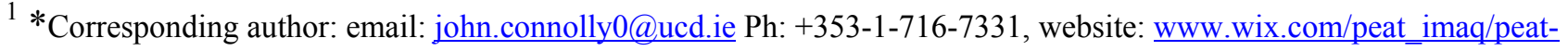
imaq
}

Remote Sensing for Agriculture, Ecosystems, and Hydrology XIII, edited by Christopher M. U. Neale, Antonino Maltese, Katja Richter, Proc. of SPIE Vol. 8174 81740G · @ 2011 SPIE · CCC code: 0277-786X/11/\$18 · doi: 10.1117/12.898573

Proc. of SPIE Vol. 8174 81740G-1 
KEYWORDS: Peatland disturbance, object-oriented, raised bogs, Ireland, Geoeye-1, high resolution imagery

\section{INTRODUCTION}

Peatlands are an important part of the global carbon cycle [1]. When peat is actively forming it sequesters carbon dioxide $\left(\mathrm{CO}_{2}\right)$ from the atmosphere creating a potentially long-term store of carbon [2] within the peatland ecosystem. If the peatland ecosystem is disturbed, peat carbon is at risk of being decomposed and emitted into the atmosphere. In Ireland peatlands are spatially extensive covering $\sim 20 \%$ of the national land area [3] and they contain between $53 \%$ and $62 \%$ of the national soil carbon stock $[4,5]$. In the midlands of Ireland the predominant peatland type is raised bogs (Figure 1). They are complex domed structures that predominantly contain organic matter and can be up to 12 metres in depth depending on the underlying topography and several metres above the surrounding landscape (Hammond, 1979). However, peatland disturbance is widespread and much of the carbon stock may be vulnerable. Connolly and Holden [6], defined peatland disturbance as "any natural or anthropogenic process that interrupts the natural trajectory of growth of the peatland".

In 1979, Hammond produced the Peatland Map of Ireland. This map recorded peatland disturbance to some extent with the "man-modified" class i.e. peat that has been disturbed and the natural vegetation altered or removed. In 1990, Cross conducted a survey of raised bogs and concluded that all sites were damaged by peat extraction and no completely intact raised bogs remained. The CORINE 2000 landcover map depicted peatland as being either "Intact" or "Exploited". In 2008, The National Parks and Wildlife Service (NPWS) classified raised bogs in Ireland as "unfavourable - bad" in terms of habitat conservation [7].

Historically raised bogs have experienced extensive disturbance including drainage, burning, erosion, domestic harvesting, and land use change [8-12]. The rate of disturbance has increased during the last seventy years [13]. This has been exacerbated in the midlands by the exploitation of raised bogs for electricity generation [12]. Bord na Mona owns about 80,000 ha and extracts peat on about 40,000 ha. Approximately 16,000 ha have already been cutaway meaning that the carbon stock in these industrial raised bogs has nearly been completely removed [14]. Pristine peatlands have also 
been exploited for forestry. Coillte Teo, the Irish forestry company, has drained and planted $\sim 196,800$ ha of peatland [15].

Understanding peatland disturbance in Ireland is a complex spatial and temporal problem. Disturbance is relatively easy to identify on the ground but it is problematic to quantify and it is difficult to create a method of determining the area where disturbance has occurred unless it is very severe. Both the historical and contemporary disturbance has lead to the development of a landscape that is characterised by a spatially complex mosaic of disturbance at both fine $\left(10 \mathrm{~m}^{2}\right)$ and coarse $\left(10 \mathrm{~km}^{2}\right)$ scales.

Human disturbance of natural landscapes can result in the imprinting of regular geometric patterns on the landscape that are very different to natural features. In peatlands this includes drainage ditches that are straight compared to natural drains i.e. streams, that meander or straight forest boundaries with angular interfaces compare to the curved boundaries of natural woodlands. Typical examples in an industrial peatland complex are the parallel drainage lines which are rarely, if ever, found in nature. Chubey et al., [16] used an object oriented approach to examine forest inventory and concluded that the approach is useful for extracting information from high resolution imagery. Evrendilek et al., [17] used an object oriented method to map the difference in peatland spatial extent from 1944 to 2009. It allowed them to quantify land use-land cover changes in a Turkish peatland. VLS Feature Analyst (FA) object oriented software was used in this paper to extract disturbance features from a high resolution Geoeye-1 satellite image. FA is an extension within ArcGIS. It uses an inductive learning-based approach to object recognition and feature extraction where the inductive learner learns from a set of labelled examples [18]. The user trains the system with a sample of extracted features in an image and the system automatically develops a model that correlates known data i.e. spectral or spatial signatures with the trained areas and can automatically classify and extract similar objects. This approach is black box, however several parameters such as feature type and spectral or textural bands can be chosen. The objective of this paper is to use object oriented image analysis to identify raised bog disturbance features in high resolution satellite imagery.

Proc. of SPIE Vol. 8174 81740G-3 


\section{METHODOLOGY}

Tullaghanrock bog is located in Co. Roscommon to the North East of Ballaghadereen (53 $54^{\prime} 49.33^{\prime \prime} \mathrm{N} 8^{\circ} 30^{\prime} 30.61^{\prime \prime}$ ), Ireland (Figure 1). According to Hammond (1979), it is a transitional raised bog with an elevation of about $70 \mathrm{~m}$ and annual precipitation of between 1000 and $1200 \mathrm{~mm}$. The raised bog has been disturbed by a road which dissects the bog as well as a large drain that runs through the middle of the bog. The edges of the bog have also been extensively cutover and there is a small area of forestry and pasture in the south-east corner (Figure 2). These disturbances are typical on raised bogs in Ireland. Much of the centre of the bog is relatively undisturbed.

\subsection{High resolution imagery}

A high-resolution multispectral image (Geoeye-1) was acquired for Tullaghanrock bog on the 13/04/2010. The image covers $73 \mathrm{~km}^{2}$ and includes peatland areas around the study sites. The Geoeye-1 product contained Blue, Green, Red and Near-Infrared bands at $2 \mathrm{~m}$ resolution and a panchromatic band at $0.5 \mathrm{~m}$ resolution. The image was georectified, orthorectified and pan-sharpened using the HPF technique in Erdas Imagine.

\subsection{Object oriented feature extraction \& disturbance}

The Derived Irish Peat Map 2 [3] was used to isolate areas of peatland from the surrounding landcover types in the image. A disturbance cube developed by Connolly and Holden [6] was used as a guide to the severity of disturbance. Disturbance affects the vegetation, carbon stock and hydrology of a peatlands. The disturbance cube captures disturbance and the severity of disturbance to these three variables with a scale; 1 = relatively undisturbed, $2=$ disturbed and $3=$ very disturbed. Feature Analyst was trained to recognise several disturbance classes including high bog, forestry, industrial peatlands, cutover areas, pasture and rough grazing areas and these were extracted from the image using the FA software. The disturbance cube combined with the feature extraction gives a good indication of the condition of the raised bog, for example, in figure 2 , high bog has a classification of 112 which means that the vegetation and carbon are relatively intact but the hydrology has been disturbed to some degree. Other areas around the edge of the bog are disturbed to a much greater extent i.e. pasture (323) and coniferous forest (322).

Proc. of SPIE Vol. $817481740 \mathrm{G}-4$ 


\subsection{Ground truthing\& Accuracy assessment}

The disturbance map for Tullaghanrock bog was ground truthed using Google Earth (GE) and assessed for accuracy [19]. Hawth's tool [20] was used to create 694 random sample points which were exported to GE. In GE they were used in to visually extract a record of disturbance on the peatland. This data base of accurate ground truth points was subsequently imported back into the GIS and intersected with the disturbance map and a confusion matrix was created to assess the map's accuracy.

\section{RESULTS \& DISCUSSION}

Peatland disturbance in Ireland is a complex spatial and temporal problem. Connolly and Holden [6] created a simple and robust method to identify peatland disturbance. The use of the DIPM2 allowed areas of peatland to be identified and the object oriented analysis combined with the disturbance cube identified the condition of these peatlands. The identification of peatland areas that have been subject to anthropogenic disturbance is useful in identifying the location of peatland carbon pools that may be vulnerable to carbon mobilisation. The method was used here in conjunction with high resolution imagery and object oriented image analysis. The method was used to identify several disturbance classes located on peatlands. These classes include areas of rough grazing, pasture, molinia, coniferous forest, drained bog, scrub as well as a relatively undisturbed area of high bog. A disturbance map was produced for Tullaghanrock bog (Figure 2). The accuracy of this map and each disturbance class was assessed. The overall accuracy for the Geoeye- 1 map of $85 \%$ was good. Many of the better classifications were for areas that are well defined both spatially and spectrally i.e. Forest (91\%). However, the method was not as accurate for the Molinia (66\%). The Molinia areas were predominantly found on the edges of the bog where cutting is evident and the bog is dryer. There was confusion between the Molinia, rough grazing and cutover areas possibly due to similar spectral signals and these areas can be very heterogeneous. SullaMenashe et al., [21] found that in the tundra biome heterogeneous shrub-dominated ecosystems containing perennial shrubs, grasses, sedges, mosses and lichens were difficult to discreetly map. In Ireland cutover and revegetating cutover areas contain a fine scale heterogeneous landscape consisting of a mix of grasses, shrubs, bare peat, sedges and mosses that are difficult to distinguish from one another and this may lead to the lower accuracy assessments for this class. 


\section{CONCLUSION}

Raised bogs in Ireland are extensively disturbed. This disturbance has been documented by Hammond [22], Cross [12], Foss [13], Bossard [23] and more recently by the NPWS [7]. In this paper we use high $(0.5 \mathrm{~m})$ resolution images from Geoeye-1 to map disturbance using an object-oriented approach. The resulting disturbance map achieved a good Overall Accuracies of $85 \%$ with individual user accuracies of up to $92 \%$. This method may be useful in other regions for the development of more accurate estimations of peatland disturbance and to identify areas of peatland ecosystems where the carbon stock may be more vulnerable to the effects of predicted climate change.

\section{ACKNOWLEDGEMENTS}

The authors wish to thank Dr. Catherine Farrell and Bord na Móna for providing the Oughter bog habitat map. We Also wish to thank the Environmental Protection Agency of Ireland for funding this research under the National Development Plan and the STRIVE Programme 2007 -2013.

\section{REFERENCES}

[1] Gorham, E. "Northern Peatlands: Role in the Carbon Cycle and Probable Responses to Climatic Warming," Ecological Applications, 1(2), 182-195 (1991).

[2] House, J. I., Orr, H. G., Clark, J. M., et al., "Climate change and the British Uplands: evidence for decision-making," Climate Research, 45, 3-12 (2010).

[3] Connolly, J. and Holden, N. M., "Mapping peat soils in Ireland: updating the derived Irish peat map," Irish Geography, 42(3), 343 - 352 (2009).

[4] Eaton, J., McGoff, N., Byrne K., et al., "Land cover change and soil organic carbon stocks in the Republic of Ireland 1851-2000," Climatic Change, 91(3), 317-334 (2008).

[5] Tomlinson, R. W., "Soil carbon stocks and changes in the Republic of Ireland," Journal of Environmental Management, 76(1), 77-93 (2005).

[6] Connolly, J. and Holden, N. M., "Classification of Peatland Disturbance," Land Degradation and Development, (In press).

[7] NPWS, [The Status of EU Protected Habitats and Species in Ireland] Department of the Environment, Heritage and Local Government, Dublin (2008).

[8] Charman, D. [Peatlands and Environmental Change] Wiley, Chichester(2002).

[9] Strack, M., Waddington, J. M., Bourbonniere, R. A., et al., "Effect of water table drawdown on peatland dissolved organic carbon export and dynamics," Hydrological Processes, 22(17), 3373-3385 (2008).

[10] Turetsky, M., Wieder, K., Halsey L., et al., "Current disturbance and the diminishing peatland carbon sink," Geophysical Research Letters 29(11), (2002). 
[11] Evans, M., and Lindsay, J., "Impact of gully erosion on carbon sequestration in blanket peatlands," Climate Research, 45, 31-41 (2010).

[12] Cross, J. R., "Survey and selection of peatland sites for conservation in the Republic of Ireland." 175-188 (1990).

[13] Foss, P., "National overview of the peatland resource in Ireland." 3-20 (1998).

[14] Renou, F., Egan, T., and Wilson, D., "Tomorrow's landscapes: Studies in the after-uses of industrial cutaway peatlands in Ireland," Suoseura, 57(4), 10 (2006).

[15] NFI, [National Forest Inventory Republic of Ireland Results], (2008).

[16] Chubey, M. S., Franklin, S. E., and Wulder, M. A., "Object-based Analysis of Ikonos-2 Imagery for Extraction of Forest Inventory Parameters," Photogrammetric Engineering \& Remote Sensing, 72(4), 383-394 (2006).

[17] Evrendilek, F., Berberoglu, S., Karakaya, N. et al., "Historical spatiotemporal analysis of land-use/land-cover changes and carbon budget in a temperate peatland (Turkey) using remotely sensed data," Applied Geography, 31(3), 1166-1172 (2011).

[18] Blundell, J. S., and Opitz, D. W., [Object recognition and feature extraction from imagery: The feature analyst ${ }^{\circledR}$ approach.] (2006).

[19] Buchanan, G. M., Butchart, S. H. M. et al., [Using remote sensing to inform conservation status assessment : Estimates of recent deforestation rates on New Britain and the impacts upon endemic birds] Elsevier, Kidlington, UK(2008).

[20] Beyer, H. L., [Hawth's Analysis Tools for ArcGIS], (2004).

[21] Sulla-Menashe, D., Friedl, M. A., Krankina, O. N., et al., "Hierarchical mapping of Northern Eurasian land cover using MODIS data," Remote Sensing of Environment, 115(2), 392-403 (2011).

[22] Hammond, R. F., “The Peatlands of Ireland,” Soil Survey Bulletin No. 35. , (1979).

[23] Bossard, M., Feranec, J., and Otahel, J. [CORINE land cover technical guide, addendum 2000] European Environment Agency, Copenhagen(2000).

Table 1. Accuracy assessment of the Ikonos (high resolution) disturbance map at Tullaghanrock bog

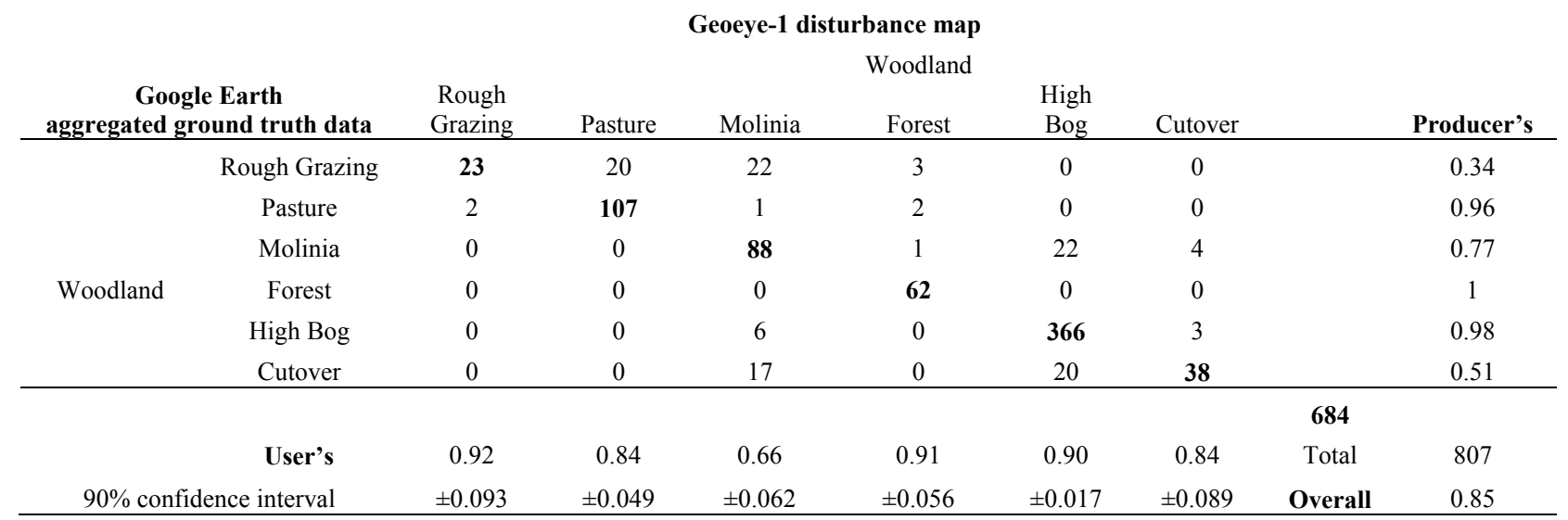




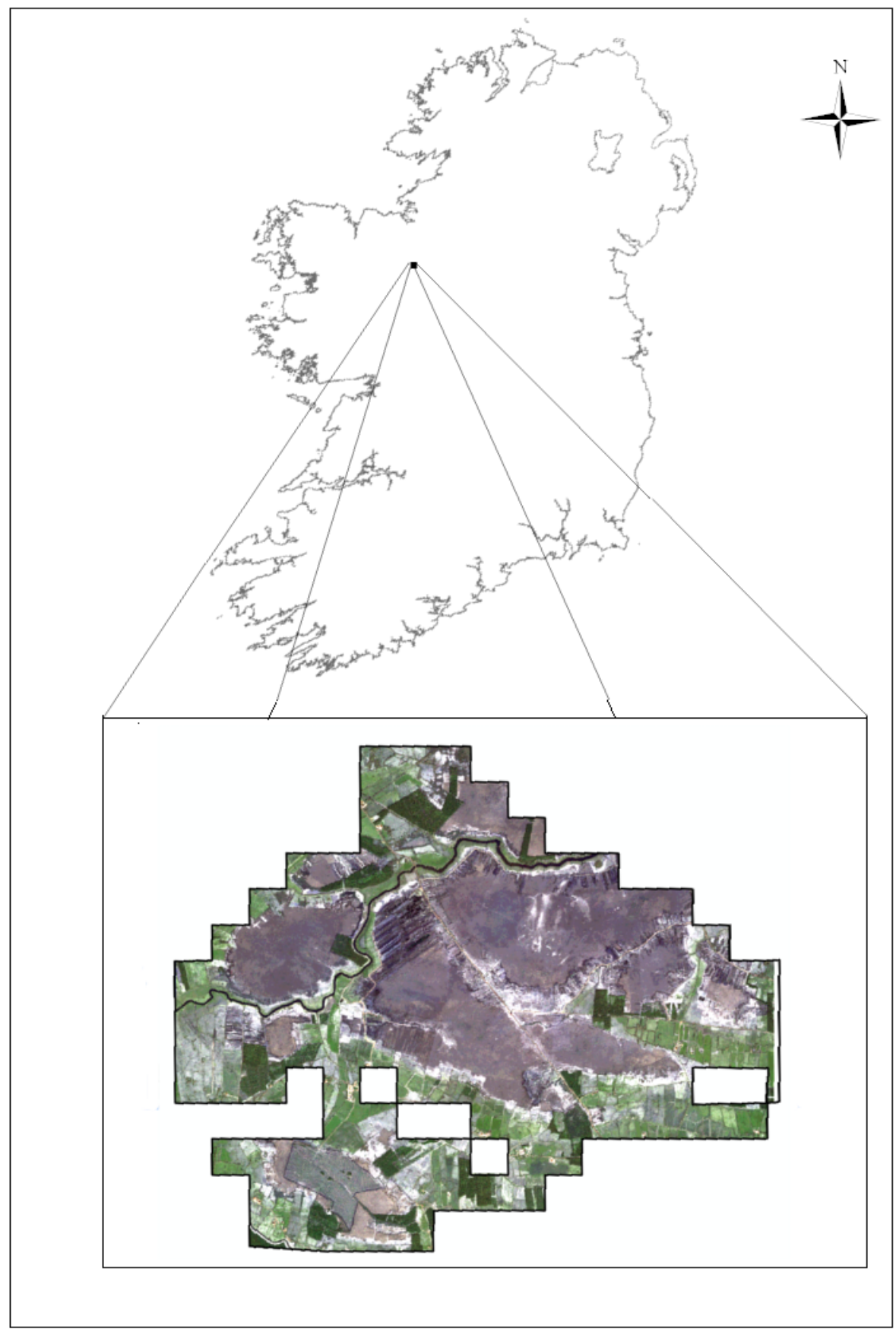

Figure 1. Location map of Tullaghanrock bog

Proc. of SPIE Vol. 8174 81740G-8 


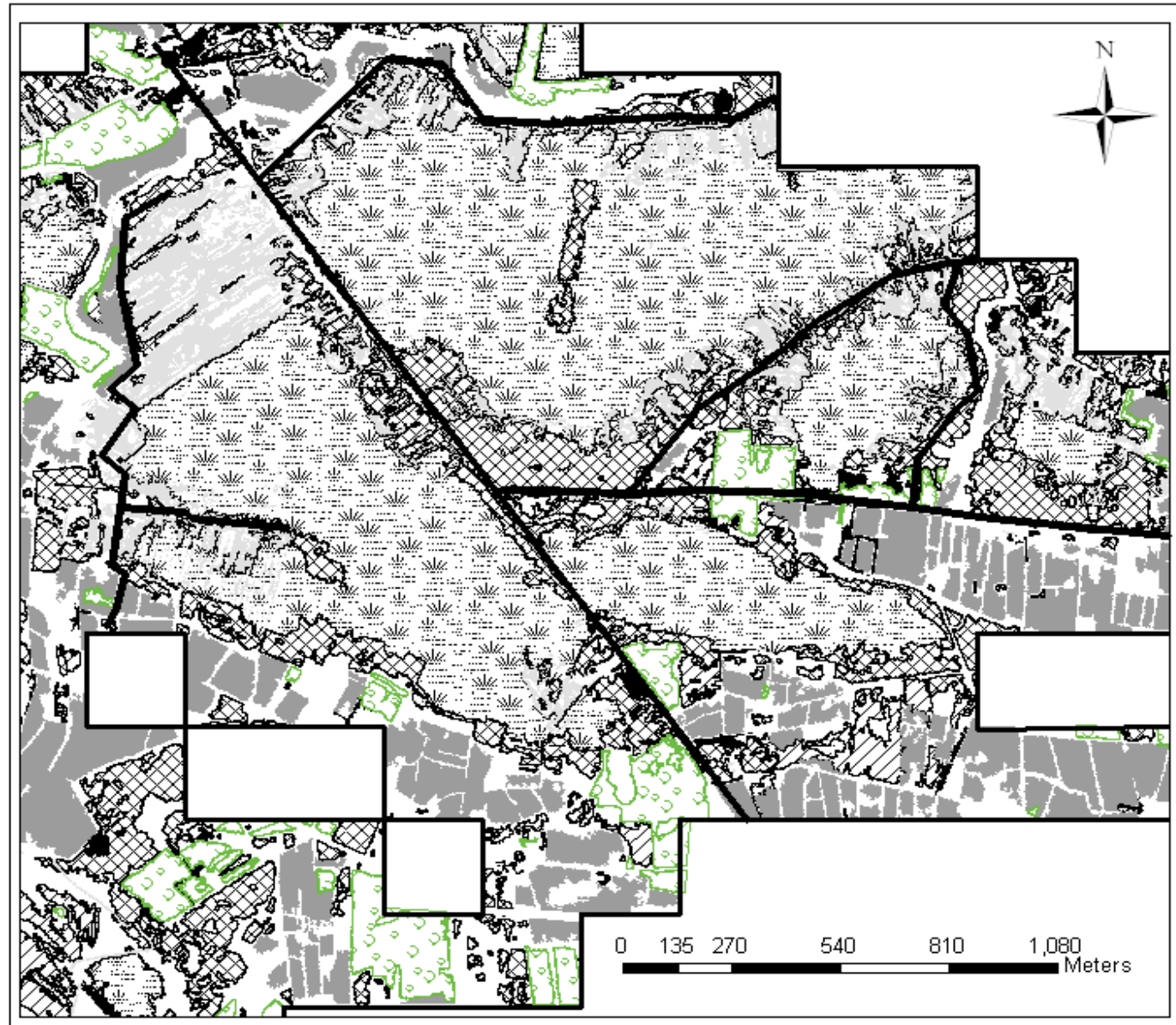

\section{Legend}

\section{High resolution Geoeye-1 disturbance $m$ ap}

Woodland_Scrub_hedge (323) High bog (112)

Q2 Rough Grazing (323) Drains (113)

Pasture (323)

\&8 Molinia (222)

DIPM2 Raised bog boundary

13 Coniferous Forest (322)

Road

\section{Figure 2. High resolution $(0.5 \mathrm{~m})$ Geoeye-1 disturbance map of Tullaghanrock bog raised bog area}

